\title{
Apoptosis Induced by Rac GTPase Correlates with Induction of FasL and Ceramides Production
}

\author{
Nieves Embade, ${ }^{*}$ Pilar F. Valerón, ${ }^{*}$ Salvador Aznar, Eduardo López-Collazo, \\ and Juan Carlos Lacal ${ }^{+}$
}

Instituto de Investigaciones Biomédicas, Consejo Superior de Investigaciones Cientificas, 28029

Madrid, Spain

Submitted January 12, 2000; Revised August 30, 2000; Accepted September 25, 2000

Monitoring Editor: Martin Raff

\begin{abstract}
Rho proteins, members of the Ras superfamily of GTPases, are critical elements in signal transduction pathways governing cell proliferation and cell death. Different members of the family of human Rho GTPases, including RhoA, RhoC, and Rac1, participate in the regulation of apoptosis in response to cytokines and serum deprivation in different cell systems. Here, we have characterized the mechanism of apoptosis induced by Rac1 in NIH 3T3 cells. It requires protein synthesis and caspase-3 activity, but it is independent of the release of cytochrome $c$ from mitochondria. Moreover, an increase in mitochondria membrane potential and the production of reactive oxygen species was observed. Rac1-induced apoptosis was related to the simultaneous increase in ceramide production and synthesis of FasL. Generation of FasL may be mediated by transcriptional regulation involving both c-Jun amino terminal kinase as well as nuclear factor- $\kappa \mathrm{B}-$ dependent signals. None of these signals, ceramides or FasL, was sufficient to induce apoptosis in the parental cell line, NIH 3T3 cells. However, any of them was sufficient to induce apoptosis in the Rac1-expressing cells. Finally, inhibition of FasL signaling drastically reduced apoptosis by Rac1. Thus, Rac1 seems to induce apoptosis by a complex mechanism involving the generation of ceramides and the de novo synthesis of FasL. These results suggest that apoptosis mediated by Rac1 results from a signaling mechanism that involves biochemical and transcriptional events under control of Rac1.
\end{abstract}

\section{INTRODUCTION}

Apoptosis, or programmed cell death, is a genetically controlled, tightly regulated process in development and morphogenesis. Unregulated excessive apoptosis may be the cause of various degenerative diseases such as Alzheimer or Parkinson (Cotman and Anderson, 1995), whereas an inappropriately low rate of apoptosis may promote survival and accumulation of abnormal cells that can give rise to autoimmune diseases and cancer (Thompson et al., 1995). During apoptosis, a cell activates an intrinsic suicide mechanism with characteristic alterations that include chromatin condensation, cytoplasmic vacuolization, plasma membrane blebbing, and DNA fragmentation (reviewed in Martin et al., 1994; White, 1996). The process of apoptosis is controlled through the expression of a number of genes conserved from nematodes through vertebrates. Some gene products are activators of apoptosis, whereas others are inhibitors (reviewed in Green, 1998).

\footnotetext{
* These authors contributed equally to this study.

+ Corresponding author. E-mail address: E-mail: jclacal@iib.uam.es.
}

It has long been accepted that some oncogenes and oncosuppressor genes are involved in cell death as well as in proliferation. The Rho GTPases form a subgroup of the Ras superfamily of GTP binding proteins that regulate a wide spectrum of cellular functions. The Rho GTPases function cycling between an active GTP-bound state and an inactive GDP-bound state. After the original cloning of rho gene in Aplysia californica (Madaule and Axel, 1985), several mammalian genes have been identified and divided into various subclasses: Rho (A, B, and C isoforms), Rac (1, 2, and 3 isoforms), Cdc42 (HsCdc42 and G25K isoforms), Rho D, Rho G, Rho E, and TC10 (Chardin et al., 1988; Didsbury et al., 1989; Shinjo et al., 1990; Vincent et al., 1992; Haataja et al., 1997).

Activated Rho GTPases interact with intracellular target proteins or effectors to trigger a wide variety of cellular responses, including the reorganization of the actin cytoskeleton, cell cycle progression, adhesion, metastasis, and gene transcription (reviewed in Van Aelst and D'Souza-Schorey, 1997). Some members of the Rho GTPase family also play a role in apoptosis. On such behalf we have previously reported that $A$. californica rho gene and the human genes rho $\mathrm{A}$, rho $\mathrm{C}$, and rac 1 are capable of inducing apoptosis in 
different cell systems such as NIH 3T3 fibroblasts and the human erythroleukemia K562 cell line after serum deprivation (Esteve et al., 1995, 1998; Jiménez et al., 1995). We have investigated the mechanism involved in this process and have demonstrated that apoptosis induced by Rho proteins is independent of p53 and is sensitive to expression of $\mathrm{Bcl} 2$ protein in vivo and in vitro (Esteve et al., 1998). Furthermore, overexpression of rho, correlated with an increase in ceramide levels (Esteve et al. 1995, 1998), a putative second messenger for apoptosis (Obeid et al., 1993; Hannun, 1994; Jarvis et al., 1994; Testi, 1996). Furthermore, it was then verified that Rho-induced apoptosis is indeed mediated by generation of ceramides. Moreover, vav and ost (Horii et al., 1994; Crespo et al., 1996) two guanine exchange factors for Rho proteins with oncogenic properties, were also able to induce apoptosis under similar conditions. We have seen also that Rho proteins play an important role in the physiological regulation of the apoptotic response to stress-inducing agents because a dominant-negative mutant of Rac 1 interferes with the induction of apoptosis by tumor necrosis factor- $\alpha$ (Esteve et al., 1998).

Numerous groups have reported that both the c-Jun amino terminal kinase (JNK) and p38 pathways can be activated by Rac and Cdc42. Moreover, we have recently demonstrated that the human Rho A, Rac-1, and Cdc42 proteins efficiently induce the transcriptional activity of nuclear factor $-\kappa \mathrm{B}(\mathrm{NF}-\kappa \mathrm{B})$, and that activation of serum response factor by Rho A is mediated by NF- $\kappa \mathrm{B}$ and CAAT enhancer binding protein $\beta(\mathrm{c} / \mathrm{EBP} \beta)$ transcription factors (Perona et al., 1997; Montaner et al., 1998, 1999). These results strongly implicate Rho proteins in the regulation of signaling pathways leading to the nucleus. Both JNK and NF- $\kappa$ B have been proposed as dual signaling pathways that can be involved in either survival/transforming or apoptotic events. Therefore, both pathways could be involved in the apoptotic responses mediated by Rho proteins. In keeping with this, recent studies indicate that overexpression of Cdc42 induces apoptosis in Jurkat cells (Chuang et al., 1997), and that this response is mediated by activation of a protein kinase cascade leading to stimulation of JNK. On the other hand, Fas-induced apoptosis is mediated by activation of Ras and Rac signaling pathway (Gulbins et al., 1996) and a new target for Rac called POSH (plenty of SH2) induces apoptosis in NIH 3T3 cells (Tapon et al., 1998). Further observations suggested that caspase- 3 is responsible for the degradation of p21, activated kinase 2 (PAK-2), a direct effector for Rac and Cdc42 proteins, and that activation of PAK-2 induces some of the morphological changes of apoptosis. Finally, it has been reported that transgenic mice carrying an activated version of the Rac2 gene, under the control of the thymus-specific lck proximal promoter, showed an increased apoptosis in the thymus, the first in vivo demonstration of a role of Rho proteins in apoptosis (Lores et al., 1997).

In an effort to elucidate the intracellular mechanism underlying the induction of apoptosis by Rho GTPases, we have investigated further the apoptotic process induced by serum deprivation in NIH 3T3 cells stably overexpressing an activated version of the Rac1 protein. A mechanism that involves ceramides production, protein synthesis, as well as caspase- 3 activation, and independent of cytochrome $c$ release has been found. Moreover, Rac-1 up-regulated the transcriptional activity of the Fas ligand promoter, thereby increasing its protein levels, by a mechanism that may involve both JNK- and NF- $\kappa \mathrm{B}$-dependent signals.

\section{MATERIALS AND METHODS}

\section{Reagents and Expression Plasmids}

Tetrapeptide inhibitors for caspase-1, acetyl-YVAD aldehyde (YVAD-CHO), caspase-3, N-acetyl DEVD-aldehyde (DEVD-CHO), and tetrapeptide substrates for caspase-3 (Ac-DEVD-AMC) and caspase-1 (Ac-YVAD-AMC) were from Research Biochemicals International (Natick, MA). Purified anti-cytochrome $c$ antibody was purchased from Pharmigen (San Diego, CA), and Rac-1 polyclonal antibody (SC217) was from Santa Cruz Biotechnology (Santa Cruz, CA). Cycloheximide and actinomycin D were from Sigma (St. Louis, $\mathrm{MO}$ ), and platelet-derived growth factor (PDGF) was from Upstate Biotechnology (Lake Placid, NY). Soluble human recombinant Fas ligand and Annexin V-FITC apoptosis detection kit were from Alexis (San Diego, CA). Recombinant mouse Fas/Fc chimera was from R\&D Systems (Minneapolis, MN), and FasL antibody was from Santa Cruz Biotechnology. To generate mass culture constitutively expressing the $r a c 1$ gene we used the expression plasmid pLNCX-rac1. This plasmid contains the human rac1 gene carrying an activating mutation (Leu 61) as a full-length cDNA under the transcriptional control of the cytomegalovirus promoter. Also the neomycin resistance gene was incorporated into the plasmid. pZIPneo plasmid and derived expression vector for constitutively active Rac1 (QL) subcloned into the BamHI site were used for transient expression assays. Fas ligand luciferase reporter constructs encoding for a $0.9-\mathrm{kb}$ fragment of the FasL promoter as well as two mutated forms in the $-1008-\mathrm{kb}$ site and $-1048 \mathrm{AP}-1$ site, respectively, were kindly provided by Dr. Douglas Green (La Jolla Institute for Allergy and Immunology, San Diego, CA).

\section{Cell Transfections}

NIH 3T3 cells were maintained in DMEM (Life Technologies, Gaithersburg, MD) supplemented with $10 \%$ newborn calf serum (NCS) under standard conditions of temperature $\left(37^{\circ} \mathrm{C}\right)$, humidity $\left(95^{\circ} \mathrm{C}\right)$, and carbon dioxide (5\%). Generation of cell lines overexpressing the indicated genes was carried out by transfection of NIH 3 T3 cells with the pLNCX-rac1 vector by the calcium phosphate method. Control cells were transfected with the empty pLNCX vector and selected as the rac1-transfected cells. The day before, cells were seeded at a density of $1 \times 10^{5}$ cells/100-mm dishes. Transfection was carried out by using $1 \mu \mathrm{g}$ of the indicated DNA and $20 \mu \mathrm{g}$ of DNA carrier. After $16 \mathrm{~h}$ of incubation, cells were washed with saline phosphate buffer and fed with DMEM supplemented with $10 \%$ NCS. One day later, geneticin (G418, Life Technologies) was added to the medium and resistant colonies were pooled $2 \mathrm{wk}$ later.

\section{Analysis of DNA Fragmentation by Ethidium Bromide Staining}

Equivalent numbers of cells $\left(3 \times 10^{5}\right)$ of each cell line were seeded into $10-\mathrm{cm}$ dishes and grown in DMEM supplemented with $10 \%$ NCS $72 \mathrm{~h}$ before treatments. After the indicated incubation periods, the total cell population (adherent and detached cells) was collected and lysed in $400 \mu \mathrm{l}$ of $100 \mathrm{mM} \mathrm{NaCl}, 10 \mathrm{mM}$ Tris-HCl, pH 8.0, 25 $\mathrm{mM}$ EDTA, $0.5 \%$ SDS. Lysates were incubated $5 \mathrm{~h}$ at $55^{\circ} \mathrm{C}$ with 0.2 $\mathrm{mg} \mathrm{ml}^{-1}$ proteinase $\mathrm{K}$, and after that the genomic DNA was precipitated at $4{ }^{\circ} \mathrm{C}$ overnight with $5 \mathrm{M} \mathrm{NaCl}$ to a final concentration of $1 \mathrm{M}$. Lysates were centrifuged at 13,000 rpm during at least $6 \mathrm{~h}$, and the pellet was eliminated. After extraction with an equal volume of phenol:chloroform:isoamyl alcohol (25:24:1, vol/vol/vol) followed by re-extraction with chloroform:isoamyl alcohol (24:1, vol/vol), DNA was precipitated at $-20^{\circ} \mathrm{C}$ overnight by addition of 0.1 volume of $3 \mathrm{M}$ sodium acetate, pH 5.3, and 1 volume of isopropanol. Precipitated DNA was collected by centrifugation at 13,000 rpm for 
$2 \mathrm{~h}$ at $4^{\circ} \mathrm{C}$, washed with ice-cold $70 \%$ ethanol, and air-dried. DNA was then resuspended in $10 \mathrm{mM}$ Tris- $\mathrm{HCl}$, pH 7.5, 1 mM EDTA (TE buffer) and treated with $0.5 \mathrm{mg} \mathrm{ml}^{-1}$ RNAse at $37^{\circ} \mathrm{C}$. DNA samples were fractionated by electrophoresis in a 1.8\% TBE-agarose gel at 60 $\mathrm{V}$ and visualized by ethidium bromide staining.

\section{Western Blot Analysis of Protein Expression}

Cells were grown under standard conditions until reaching $75 \%$ confluence, or serum-starved until needed in the experiment. Cells were washed twice with TD buffer (137 mM NaCl, $5 \mathrm{mM} \mathrm{KCl}, 1 \mathrm{mM}$ $\mathrm{Na}_{2} \mathrm{HPO}_{4}, 20 \mathrm{mM}$ Tris, $\mathrm{pH}$ 7.4), and lysed in $300 \mu \mathrm{l}$ of ice-cold lysis buffer (50 mM Tris, pH 7.4, 0.25\% NP-40, 0.25\% SDS, $150 \mathrm{mM} \mathrm{NaCl}$, $15 \mathrm{mM} \beta$-glycerophosphate, $10 \mathrm{mM} \mathrm{NaPPi}, 50 \mathrm{mM} \mathrm{NaF}, 10 \mu \mathrm{g} / \mu \mathrm{l}$ aprotinin, $1 \mathrm{mM}$ phenylmethylsulfonyl fluoride). Nuclei and detergent-insoluble material were removed by centrifugation at 13,000 rpm for $15 \mathrm{~min}$. The resulting supernatants were analyzed for estimation of total cell protein (Bio-Rad, Las Rosas, Spain), and equal amounts of cell lysates $(30 \mu \mathrm{g})$ were boiled at $95^{\circ} \mathrm{C}$ for $3 \mathrm{~min}$ in SDS-polyacrylamide gel electrophoresis sample buffer. For Western blot analysis, proteins were electrophoresed onto 15\% (cytochrome $c$ ), 12\% (Rac1), or 10\% (Fas Ligand) gels. Resolved proteins were transferred to nitrocellulose and blots were blocked in 5\% nonfat dried milk in TTBS $(0.05 \%$ Tween 20$)$ and were incubated with the appropriate antibodies at 1/1000 dilutions and developed by enhanced chemiluminescence (Amersham, London, United Kingdom).

\section{Reverse Transcription-Polymerase Chain Reaction (RT-PCR) for FasL Expression}

The expression of FasL was determined by RT of total RNA followed by PCR. Cells were grown under $75 \%$ confluence, and where indicated, serum was removed for $24 \mathrm{~h}$. Then the cells were washed twice with TD, and total RNA was isolated with an UltraespecIIRNA isolation kit (Biotecx, Las Rosas, Spain) according to the manufacturer's protocol. cDNA was synthesized by extension of primers with avian myeloblastosis reverse transcriptase (Promega, Madison, WI) in a mixture containing $1 \mu \mathrm{g}$ of total RNA during $1 \mathrm{~h}$ at $37^{\circ} \mathrm{C}$. PCR of the cDNA was performed in a final volume of $20 \mu \mathrm{l}$ containing all four dNTPs, $1.5 \mathrm{mM} \mathrm{MgCl} 2,2.5$ units of AmpliTaq (Perkin Elmer-Cetus, Norwalk, CT), and each primer at $0.2 \mu \mathrm{M}$ by using the geneAmp 2400 PCR system (Perkin Elmer-Cetus). The amplification cycles were $92^{\circ} \mathrm{C}$ for $20 \mathrm{~s}, 55^{\circ} \mathrm{C}$ for $30 \mathrm{~s}$, and $72^{\circ} \mathrm{C}$ for $1 \mathrm{~min}$. The PCR products were resolved by electrophoresis on a $1.6 \%$ agarose gel after 40 cycles (471-bp human FasL fragment) or after 20 cycles (400-bp human $\beta$-actin) and visualized by ethidium bromide staining. Amplification of $\beta$-actin served as control for sample loading and integrity. The following primers were designed to discriminate between the amplification of cDNA and contaminating genomic DNA: hFasL-forward: 5'-TAAAACCGTTTGCTGGGGC-3', hFasL-reverse: 5'-CTCAGCTCCTTTTTTCAGGGG-3' $\beta$-actin-forward: 5'-AATCTGGCACCACACCTTCTACA-3', and $\beta$-actin-reverse: 5'-CGACGTAGCACAGCTTCTCCTTA-3'.

\section{Measurement of Protease Activity}

Cells with or without serum treatment were lysed with $300 \mu \mathrm{l}$ of $0.5 \% \mathrm{NP}-40,0.5 \mathrm{mM}$ EDTA, $150 \mathrm{mM} \mathrm{NaCl}$, and $50 \mathrm{M}$ Tris, $\mathrm{pH} 7.5$. Aliquots $(50 \mu \mathrm{l})$ of the extracts were incubated with $40 \mu \mathrm{M}$ tetrapeptide substrate, $10 \mathrm{mM}$ HEPES, pH 7.5, $0.05 \mathrm{M} \mathrm{NaCl}$, and $2.5 \mathrm{mM}$ DTT in $200 \mu \mathrm{l}$ of reaction mixture for $2 \mathrm{~h}$ at $37^{\circ} \mathrm{C}$. The fluorescence of released 7-amino-4-methyl-coumarin (AMC) was measured by using an excitation wavelength of $365 \mathrm{~nm}$ and an emission wavelength of $450 \mathrm{~nm}$.

\section{Isolation of Mitochondria and Preparation of Mitochondrial Extracts}

The cells were submitted to the indicated treatments, washed twice with TD, and tripsinized by using isolation medium $(0.32 \mathrm{M}$ su- crose, $1 \mathrm{mM}$ EDTA, $10 \mathrm{mM}$ Tris- $\mathrm{HCl}[\mathrm{pH} 7.4]$ ), and $0.1 \%$ bovine serum albumin (fatty acid free). Then, cells were homogenized manually with a Potter-Ewelgein and samples centrifuged at $2000 \times$ $g$ for $3 \mathrm{~min}$. The precipitate was discarded, and the supernatant was centrifuged again at $12,500 \times g$ for another $10 \mathrm{~min}$ to yield the crude mitochondrial pellet. To the supernatant (the cytosolic fraction) protein inhibitors $1 \mathrm{mM}$ phenylmethylsulfonyl fluoride, and 10 $\mu \mathrm{g} / \mathrm{ml}$ aprotinin (Sigma) were added, and samples stored at $-70^{\circ} \mathrm{C}$ until further analysis by Western blot. The mitochondrial pellet was resuspended in lysis buffer $(20 \mathrm{mM}$ Tris- $\mathrm{HCl}, \mathrm{pH}$ 8.0, 0.2 mM EDTA, $10 \%$ glycerol, $0.35 \mathrm{M} \mathrm{NaCl}, 1 \%$ Triton $\mathrm{X}-100$, and $1 \mathrm{mM}$ DTT). The mitochondrial suspension was vigorously vortexed and allowed to stand on ice for $15 \mathrm{~min}$. The mitochondrial lysate was then centrifugated at 45,000 rpm for $1 \mathrm{~h}$. Protein was determined in the supernatant and fractions were frozen and stored at $-70^{\circ} \mathrm{C}$ until further analysis for cytochrome $c$ content by Western blot analysis with a specific antibody as described above.

\section{Transient Transfections}

Murine NIH 3 T3 fibroblasts were grown in DMEM with 10\% newborn calf serum, $1 \mathrm{mM}$ glutamine (Life Technologies) and 25,000 units of penicillin and $25,000 \mu \mathrm{g} / \mathrm{ml}$ streptomycin (Life Technologies). For transient expression assays, cells were transfected in 60-mm dishes by the calcium phosphate method as described in Montaner et al. (1999). The amount of plasmidic DNA was kept constant at $10-12 \mu \mathrm{g} /$ plate with the corresponding empty vector, and the total amount of DNA was kept at $25 \mu \mathrm{g} / 60-\mathrm{mm}$ dish with calf thymus DNA (Boehringer Mannheim, Basel, Switzerland). After the precipitate was removed, cells were incubated in DMEM, $0.5 \%$ fetal bovine serum for $24 \mathrm{~h}$ and harvested for luciferase assay as described in Montaner et al. (1999).

\section{Gene Expression Analysis}

Analysis of the FasL promoter activity was performed by cotransfection of the expression vector for Rac1-QL with the hFasL-Luc reporter or its mutated forms in the $\kappa \mathrm{B}$ site or AP-1 site separately. Cells were harvested $24 \mathrm{~h}$ after transfection and the protein extracts were prepared by lysis with $150 \mu \mathrm{l} / 60-\mathrm{mm}$ dish of $1 \times$ cell culture lysis reagent (Promega) containing $25 \mathrm{mM}$ Tris-phosphate, $\mathrm{pH} 7.8,2$ $\mathrm{mM}$ DTT, $2 \mathrm{mM}$ 1,2-diaminocyclohexane- $N, N, N^{\prime}, N^{\prime}$-tetraacetic acid, $10 \%$ glycerol, and $1 \%$ Triton X-100. The total amount of protein was determined with a commercial kit based on the Bradford method (Bio-Rad). Protein $(20 \mu \mathrm{g})$ was assayed for luciferase activity by using a commercial kit (Promega).

\section{Analysis of Changes in Mitochondrial Transmembrane Potential}

To measure $\Delta \Psi \mathrm{m}$, both NIH 3T3 and Rac-1-transfected cells grown in the presence or absence of serum were incubated with $100 \mathrm{nM}$ JC-1 (Molecular Probes, Eugene, OR) added to the culture media for $15 \mathrm{~min}$ at $37^{\circ} \mathrm{C}$. Cells were then washed in phosphate-buffered saline and analyzed on a FACScan flow cytometer (Becton Dickinson, Mountain View, CA) by using both the green (FL-1) and red (FL-3) channels. At least 10,000 events were collected per sample.

\section{Measurement of Reactive Oxygen Species (ROS) Production and Cell Viability in Relation with Changes in $\Delta \Psi \mathrm{\Psi}$}

Cells were incubated during $15 \mathrm{~min}$ at $37^{\circ} \mathrm{C}$ with the potentialsensitive dye 3,3'-dihexyloxacarbocyanine iodide, $40 \mathrm{nM}$ (DioC6; Molecular Probes) and the ROS-sensitive dye hydroethidine, $2 \mathrm{mM}$ (HE; Molecular Probes). After incubation, cultures were washed in phosphate-buffered saline and analyzed on a FACScan flow cytometer. To determine the relationship between viability and changes in 
A

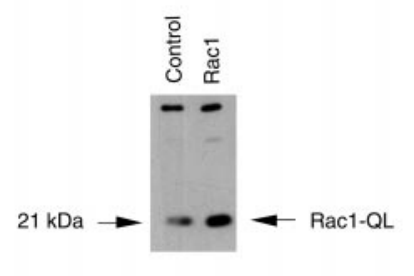

B

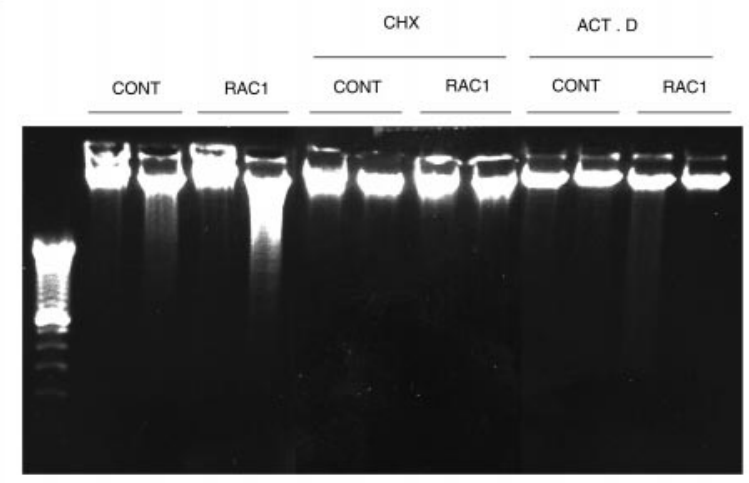

Figure 1. Induction of apoptosis by overexpression of the human Rac protein needs mRNA and proteins synthesis. (A) NIH $3 \mathrm{~T} 3$ cells were transfected with the appropriate plasmids carrying the human gene rac- 1 activated by a Leu 61 mutation (QL mutant). Pools of transfected cells were selected for geneticin resistance and equivalent amounts of protein lysates were analyzed by Western blot for the level of expression of the protein by using a specific antibody. Control indicates extracts from cells transfected with the empty vector, pLNCX. Rac1 indicates the constitutively active pLNCXRac1 QL mutant. The arrow on the right indicates the position of Rac1QL protein. (B) Analysis of apoptosis by the DNA fragmentation assay after serum deprivation. Cells were incubated for $24 \mathrm{~h}$ in DMEM with or without serum and in presence of $50 \mu \mathrm{M}$ cycloheximide (CHX), actinomycin D (ACT. D). Gel shows the DNA ladder after staining with ethidium bromide.

$\Delta \Psi \mathrm{m}$, DioC6-stained cells were incubated with propidium iodine (PI) during $10 \mathrm{~min}$ as described in López-Collazo et al. (1998).

\section{RESULTS}

\section{Apoptosis Induced by Rac in NIH 3 T3 Requires Protein Synthesis}

We have previously demonstrated that overexpression of the rho gene from A. californica and the human rho A, rac-1, and rho C genes in NIH 3 T3 cells can induce apoptosis under serum deprivation (Esteve et al., 1995, 1998; Jiménez et al., 1995). To better understand the mechanisms involved in this process, we have focused on rac-1 gene. To that end, we first established an NIH $3 \mathrm{~T} 3$ fibroblast cell line that stably ex- presses the oncogenic version of Rac-1 protein, which contains a mutated leucine 61 (Rac1). After transfection with calcium phosphate and selection for neomycin resistance, cells were characterized by Western blot by using a Rac1specific antibody (Figure 1A). Apoptosis in the rac transfectants was measured by DNA fragmentation after serum deprivation. As shown in Figure 1B, a clear DNA degradation pattern, typical of cell death by apoptosis, was observed in the selected cells overexpressing the Rac1 protein. By contrast, the parental NIH 3T3 cells, transfected with the empty plasmid and selected for neomycin resistance, showed no significant internucleosomal DNA degradation under similar conditions (Figure 1B).

We treated cells with actinomycin D or cycloheximide to test whether protein synthesis was necessary to induce apoptosis or whether all the components necessary for apoptotic signal transduction were already present in cells (Figure 1B). Rac-induced apoptosis was inhibited in the presence of both inhibitors, an indication that protein synthesis was required. We tested whether growth factors such PDGF were capable of suppressing apoptosis induced by serum deprivation in the Rac1-expressing cells. As shown in Figure $2 \mathrm{~A}$, apoptosis induced by Rac1 under serum starvation was completely inhibited by PDGF. The same effect was observed when fibroblast growth factor (FGF) was used under similar conditions (our unpublished results). Thus, specific growth factors can provide survival signals that prevent cells expressing Rac1 to undergo apoptosis after serum deprivation.

\section{Caspase-3 Mediates Rac1-induced Apoptosis}

Apoptotic responses in most cells are known to involve the activity of specific proteases called caspases. Caspases 8 and 9, known as initiator caspases, have been widely linked to the central pathway of apoptosis induction, whereas caspase-3 appears to be required for many of the characteristic apoptotic nuclear changes and is therefore termed an effector caspase (reviewed in Nuñez et al., 1998). Specific competitive inhibitors and fluorescent substrates have been designed for caspase- 1 and -3 from knowledge of their sequence recognition specificity. Cell death can be blocked upon treatment of cells with these specific inhibitors (Nicholson et al., 1995).

To test whether Rac1 initiated an apoptotic signal mediated by some caspases we evaluated the effect of caspase inhibitors on the apoptotic responses induced by Rac1. Caspase-3 recognizes Asp-Glu-Val-Asp (DEVD) and the aldehyde DEVD-CHO has been proved to be a specific inhibitor of this protease. Treatment of cells overexpressing Rac1-QL with DEVD-CHO inhibited the cell death induced by serum deprivation but had no effect in control cells (Figure 2A). In contrast to DEVD-CHO, the YVAD-CHO peptidem, which inhibits specifically caspase- 1 and recognizes the sequence Tyr-Val-Ala-Asp (YVAD), was not effective in blocking the apoptotic response at the same concentration as that of DEVD-CHO. Furthermore, treatment of cells with double the concentration of caspase- 1 inhibitors still had no effect in Rac-1-overexpressing cells or control cells. Therefore, YVAD was a negative control, in agreement with the fact that caspase- 1 is implicated mostly in inflammatory processes but not in apoptosis in most of the cell types investigated (Thornberry and Lazebnik, 1998). Viabil- 


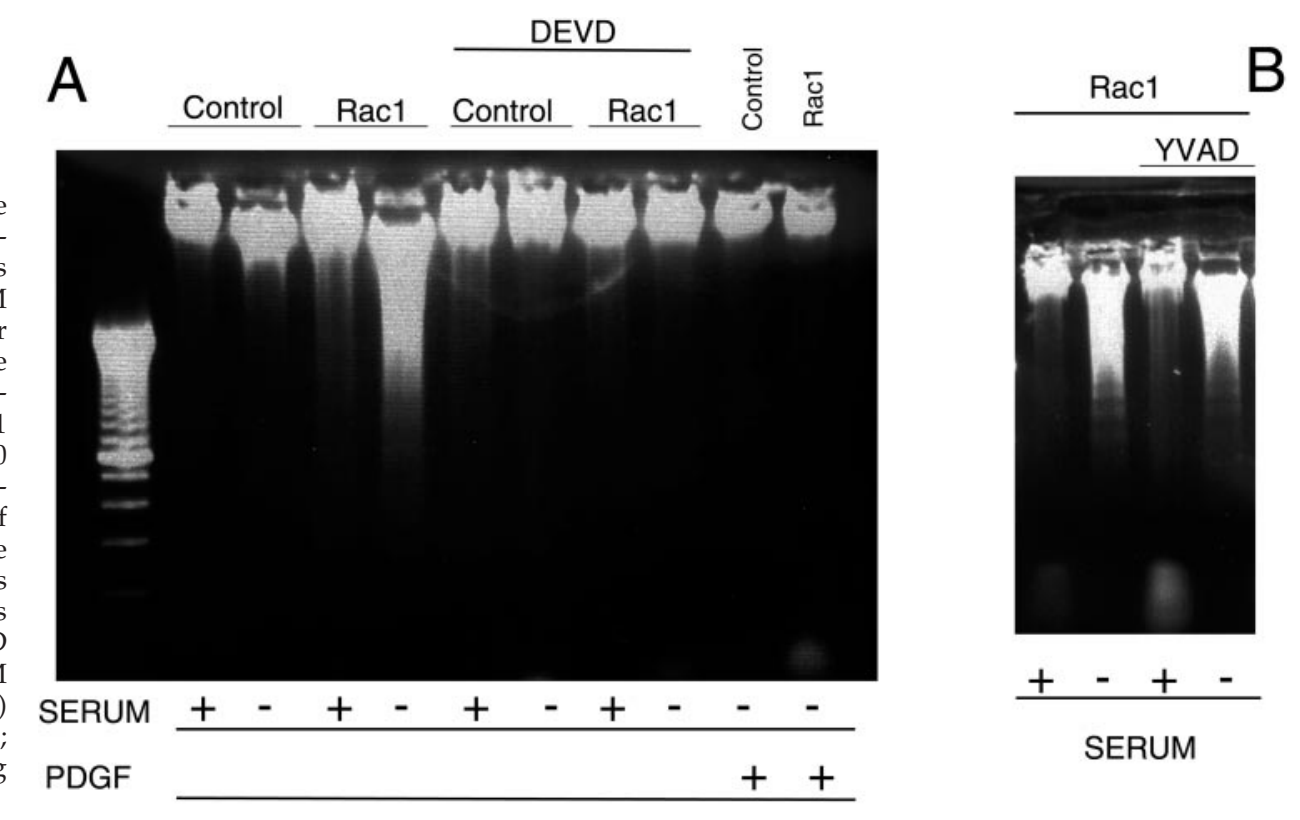

Figure 2. Effect of caspase protease inhibitors on Rac-induced apoptosis. Rac1 and control NIH 3T3 cells were incubated in either DMEM supplemented with $10 \%$ NCS (+) or DMEM without serum $(-)$. The caspase-3 inhibitor acetyl-DEVDCHO $(50 \mu \mathrm{M})(\mathrm{A})$ or the caspase-1 inhibitor acetyl-YVAD-CHO (100 $\mu \mathrm{M})(\mathrm{B})$ was added and cells incubated for an additional period of $24 \mathrm{~h}$. After this period, cells were analyzed for induction of apoptosis by the DNA fragmentation analysis as described in MATERIALS AND METHODS. Where indicated, DMEM supplemented with PDGF (100 nM) was used. Control, NIH 3T3 cells, Rac1, NIH 3T3 cells overexpressing the mutated Rac1-QL protein.

ity and aspect of cells overexpressing the Rac1 protein in the absence of serum and treated with protease inhibitors was similar to control cells, and no signs of death were detected by DNA analysis (Figure 2B).

The above-mentioned results suggested that Rac1-induced apoptosis is mediated by caspase- 3 but not by caspase-1. To further confirm that caspase- 3 activation was involved in Rac1-induced apoptosis, cytosolic extracts from serum-depleted cells overexpressing Rac1-QL were subjected to protease activity assay by using tetrapeptide substrates that incorporate a photometric cleaving group (AMC). Enzymatic cleavage after DEVD treatment was detected in Rac-1 overexpressing cells as early as $6 \mathrm{~h}$ after serum deprivation and increased thereafter at 12 and $24 \mathrm{~h}$ (Figure 3). However, no increase in caspase-1 protease activity was detected under similar conditions (Figure 3), consistent with the failure of the tetrapeptide YVAD-CHO to prevent Rac-induced apoptosis (Figure 2). Cell lines expressing Rac1 and grown in the presence of serum showed only a partial activity for caspase-3, equivalent to one-tenth of that observed in the serum-deprived cells. Moreover, parental NIH 3T3 cells showed only a marginal increase of caspase-3 activity under similar experimental conditions. These results taken together confirm that programmed cell death induced by serum deprivation in cells overexpressing activated Rac1 involves caspase- 3 but not caspase- 1 .

\section{Rac1-induced Apoptosis Occurs in the Absence of Cytochrome c Release to the Cytosol}

Cytochrome $c$ is a mitochondrial protein involved in the respiratory chain. This molecule is encoded by a nuclear gene and synthesized as a cytoplasmic precursor molecule, apocytochrome $c$, which is translocated to mitochondrial intramembranous space. Translocation of cytochrome $c$ from mitochondria to cytosol has been shown to be a crucial step in activation of the programmed cell death in various death models (Krippner et al., 1996; Liu et al., 1996; Kluck et al., 1997; Yang et al., 1997). Once released, it interacts with other cytoplasmic components to initiate the activation of the execution caspases, which leads to the subsequent apoptosis.

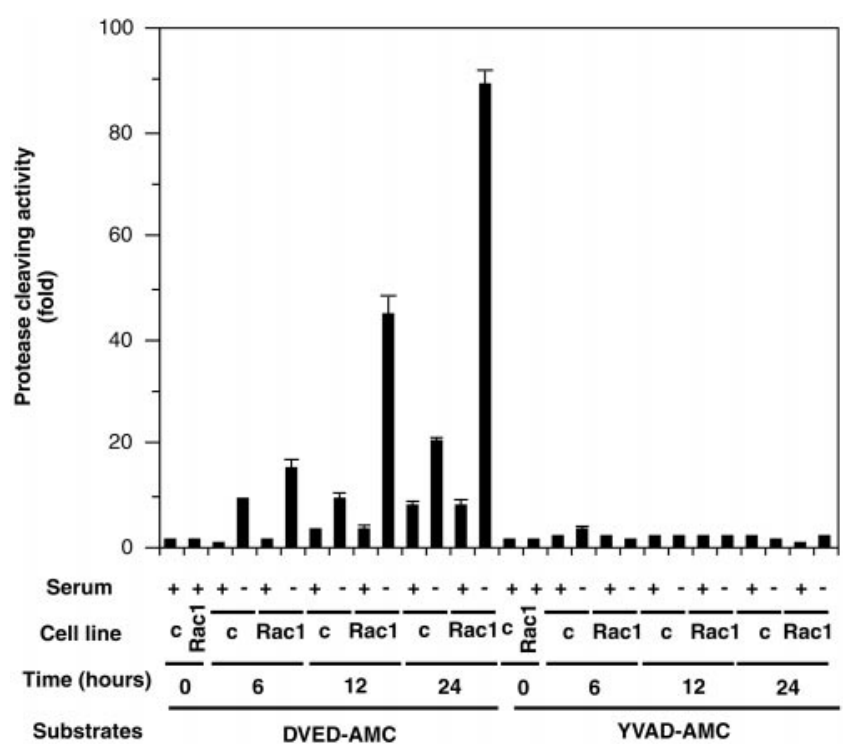

Figure 3. Caspase-3 activation in apoptosis induced by Rac1. NIH 3 T3 cells constitutively expressing the Rac1QL protein and cells transfected with the empty plasmid (c) were cultivated for $24 \mathrm{~h}$ in DMEM supplemented with $10 \%$ new born calf serum $(+)$ or DMEM without serum $(-)$. The cells were collected at $0,6,12$, and $24 \mathrm{~h}$ after treatment and cytoplasmic extracts were tested for protease activity by using specific substrates as indicated in MATERIALS AND METHODS Caspase-1 and caspase-3 enzyme activity is expressed as fold activation over basal levels. Data are representative of four experiments performed in triplicates, with similar results. Bars represent SD. 


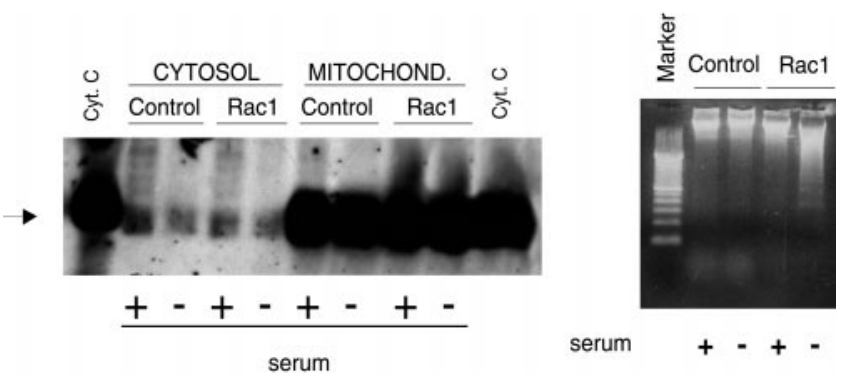

Figure 4. Rac1-induced apoptosis progress in the absence of cytochrome $c$ accumulation in the cytosol. (Left) NIH 3T3 cells (Control) and Rac1-expressing cells (Rac1) were incubated in DMEM medium with (+) or without (-) serum for $24 \mathrm{~h}$. After that, cells extracts were obtained and processed for cytochrome $c$ analysis. Both cytosolic (Cytosol) and mitochondrial preparations (Mitochond.) were tested for the presence of cytochrome $c$ by Western blot analysis, by using a monoclonal antibody against cytochrome $c$. Cyt. C indicates purified cytochrome $c$. The arrow indicates the position of the cytochrome $c$. (Right) Parallel cultures of NIH 3T3 cells (Control) and Rac1-expressing cells (Rac1) were incubated in DMEM medium with $(+)$ or without $(-)$ serum for $24 \mathrm{~h}$ cells and then analyzed for induction of apoptosis by the DNA fragmentation analysis as described in MATERIALS AND METHODS.

Liu et al. (1996) demonstrated that cytochrome $c$ is required for the activation of caspase-3. However, some apoptotic pathways can act independently of cytochrome $c$ release. To test whether there was translocation of cytochrome $c$ from mitochondria to cytosol in our system, we treated the cells with or without serum, isolated the mitochondria and cytosol by differential centrifugation, and performed a Western blot analysis by using a monoclonal antibody against cytochrome $c$ (Figure 4A). Cytosol from cells incubated in the absence of serum, therefore, induced to apoptosis, did not show any significant increase in the content of cytochrome $c$ protein at a time when apoptosis was detectable by the appearance of the DNA ladder (Figure 4B). Furthermore, in these serum-starved cells, cytochrome $c$ was clearly detectable in the mitochondria at similar levels to those of control cells. Finally, the results observed in the Rac1-expressing cells were not distinguishable from those of the parental cells in the presence or absence of serum deprivation. The above-mentioned results indicate that the cytosolic accumulation of cytochrome $c$ is not an event involved in triggering apoptosis in the Rac1-expressing cells.

\section{Rac-1 Increases ROS Production and Elevates the Membrane Potential of the Mitochondria}

The lack of a clear role for cytochrome $c$ led to the search of other targets that could be involved in apoptosis induced by Rac-1. In the following experiments we investigated the early changes in $\Delta \Psi \mathrm{m}$ and production of ROS. Although $\mathrm{NIH} 3 \mathrm{~T} 3$ cells did not exhibit significant changes in $\Delta \Psi \mathrm{m}$ after serum deprivation, determined by JC-1 staining, a clear hyperpolarization was observed in the rac1-transformed cells $4 \mathrm{~h}$ after serum starvation. The rise of JC-1 red fluorescence (FL-3) in this cell line indicates an increase of $\Delta \Psi \mathrm{m}$
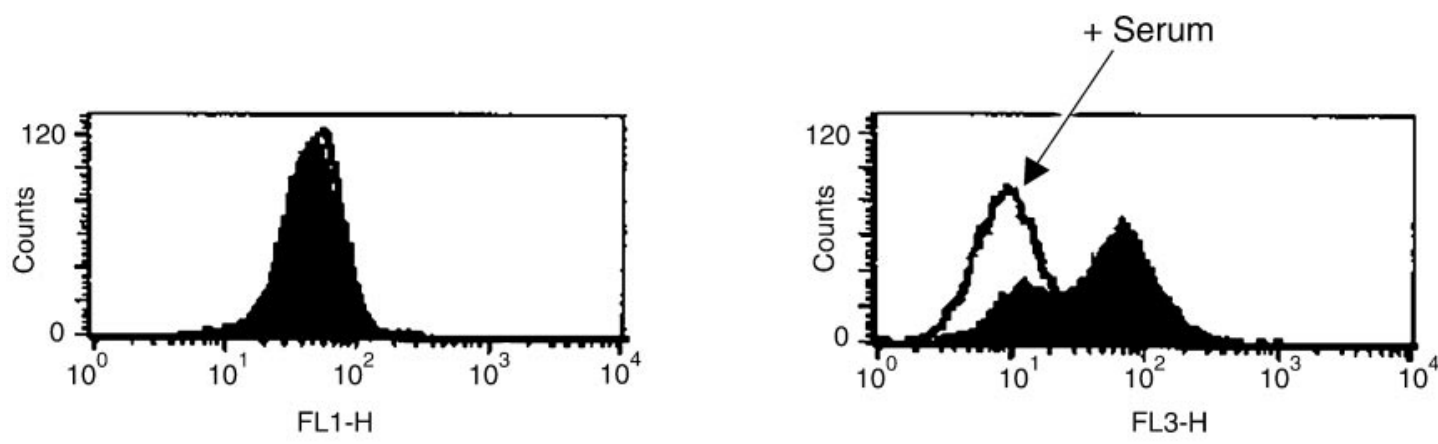

Rac1
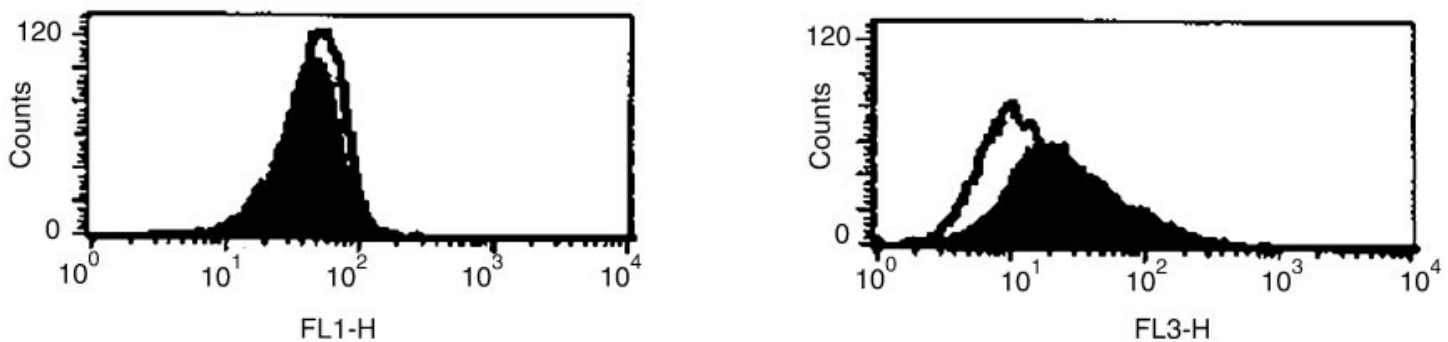

Control

Figure 5. Rac1 induces mitochondrial hyperpolarization. Rac1-transformed cells and NIH 3T3 cells were cultured in the presence or absence of serum during $4 \mathrm{~h}$. Changes in $\Delta \Psi \mathrm{m}$ were measured by using JC-1 uptake by flow cytometry in both green (FL-1) and red (Fl-3) channels. White peaks represent JC-1 uptake in the presence of serum (arrow), whereas colored peaks indicate JC-1 stained cells under serum deprivation conditions. A representative result of three experiments is shown. 
Rac1
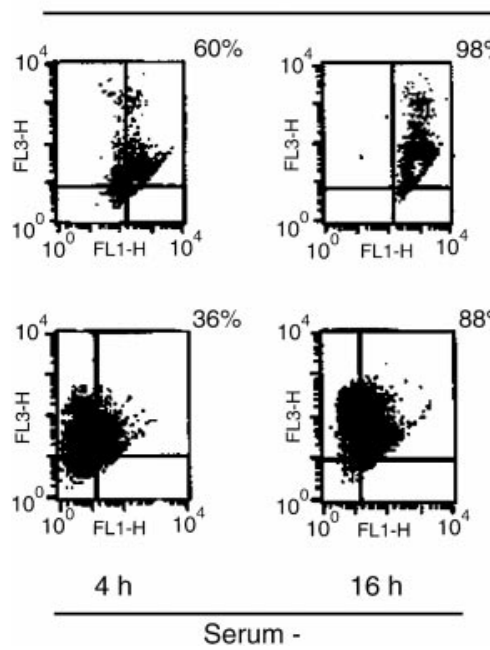

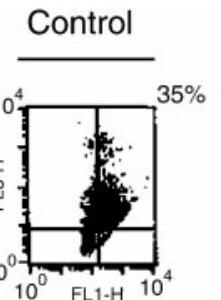

A

B
Figure 6. Rac1 increases both $\Delta \psi$ and ROS production. (A) Analysis of $\Delta \psi$ alterations by DioC6 (FL-1) and cellular death by PI (FL-3) at indicated times. (B) Relationship between ROS production and changes in $\Delta \psi$. ROS were detected by using HE (FL-3). Two representative results of four experiments are shown.
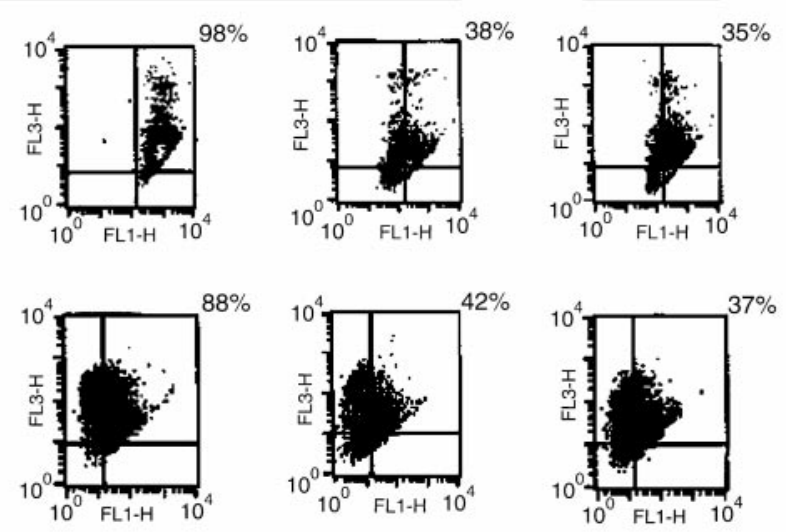

$16 \mathrm{~h}$

Serum +
$16 \mathrm{~h}$

Serum -
(Figure 5). However, fluorescence in this channel was reduced after $24 \mathrm{~h}$ of serum deprivation in Rac-1-transformed cells, probably due to the disruption of the mitochondrial inner membrane and a concomitant loss of $\Delta \Psi \mathrm{m}$ at this time (our unpublished results). These results were confirmed by double staining with the dye DioC6 (sensitive to membrane potential) and the vital dye PI, where we observed early changes of $\Delta \Psi \mathrm{m}$ (FL-1), specifically in the rac1 cells after serum withdrawal (Figure 6). As well, high changes were observed at $16 \mathrm{~h}$ of serum starvation in the same cell line, which were accompanied by an elevation in the PI fluorescence (FL-3). This suggests a relationship between mitochondrial membrane hyperpolarization and cell death in this context (Figure 6). Furthermore, an increase in ROS levels in rac1-transformed cells was observed at $16 \mathrm{~h}$ after serum deprivation, determined by a significant elevation of red fluorescence of HE-stained cells, suggesting a possible role for these species in the cell death.

\section{Fas Ligand Is Synthesized in Rac1-induced Apoptosis and It Is Required for Induction of Apoptosis}

The Fas/Fas ligand (FasL) pathway has been implicated as an important cellular pathway mediating apoptosis in diverse cell types (reviewed in Ashkenazi and Dixit, 1999). Other reports demonstrated that activation via the FasL receptor stimulates the acid sphingomyelinase, leading to synthesis of ceramide (Gulbins et al., 1996). We have reported previously that in rho- and rac-transfectants the levels of ceramides increase upon serum removal (Esteve et al., 1995, 1998). In parallel, a reduction of the levels of sphingomyelin is observed, an indication that an endogenous sphingomyelinase may be involved.

Next, we wanted to establish the possible correlation between induction of apoptosis by Rac and synthesis of FasL. To examine this possibility we tested the expression of FasL in Rac1-QL-overexpressing cells by using RT-PCR under serum deprivation conditions. As shown in Figure 7A, FasL mRNA expression was clearly observed in serum-starved
Rac1-QL-overexpressing cells but not in serum-depleted control cells or in Rac1-QL cells grown with $10 \%$ NCS. Amplification of $\beta$-actin was tested in all cell lines and served as a control for sample loading and integrity. No difference was observed in any of the samples tested. Similar results were observed when the levels of FasL were tested by Western blot analysis with a FasL antibody. As shown in Figure 7B, the levels of FasL were strongly increased in serum-starved cells. Finally, we examined whether induction of FasL was necessary for Rac-1-induced apoptosis. To that end, cells were serum starved or kept in the presence of serum and treated or not with $\mathrm{FasFc}$, an antogonist of FasL signaling (Fan et al., 1999). As shown in Figure 7C, FasFc treatment induced a $50 \%$ reduction in the apoptotic response. Thus, these results indicate that expression of Rac1 activates FasL synthesis, and that production of FasL is necessary for the apoptotic response.

\section{Rac1 Activates Fas Ligand Synthesis by Transcriptional Regulation of Its Promoter}

The above-mentioned results demonstrate the induction of FasL synthesis by Rac1 after serum deprivation. Previous results have demonstrated that FasL is regulated at transcriptional levels by regulation of its promoter (Green and Reed, 1998). Thus, we next investigated whether Rac-1 was able to transcriptionally activate the Fas ligand promoter. NIH 3T3 cells were cotransfected transiently with a plasmid containing the FasL promoter joined to the luciferase gene as a reporter, along with an increasing dose of the expression plasmid containing the rac-1 gene. The results shown in Figure 8 indicate that expression of the rac-1 gene induces the transcriptional activation of the FasL promoter up to 2.5-fold, an effect that was dose-dependent upon the amount of rac1 DNA used in the transfection. Moreover, this induction did not occur when rac1 was cotransfected with a mutated version of the FasL promoter with an inactive NF- $\kappa \mathrm{B}$ site or an inactive AP-1 site. These results suggest that these two signaling cascades (JNK-dependent and NF- $\kappa$ B-depen- 
A

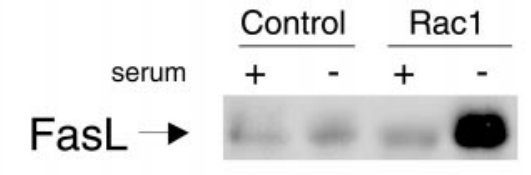

C

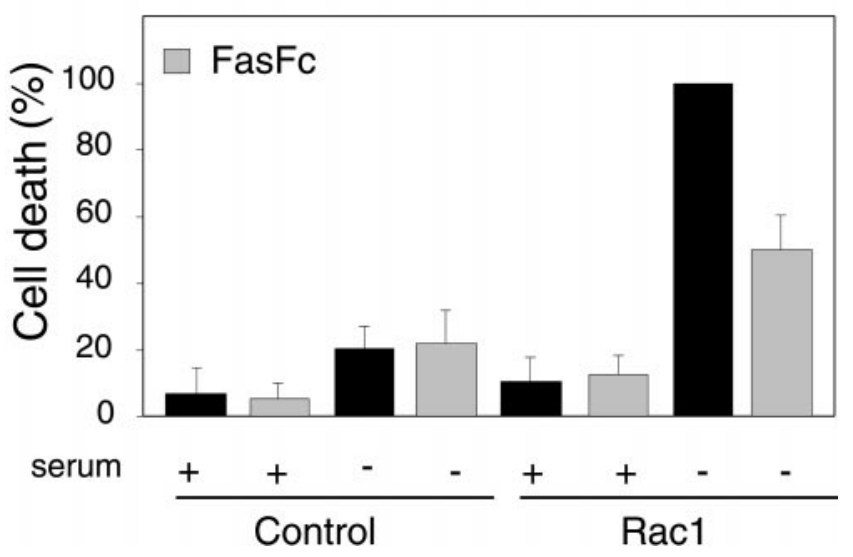

Figure 7. FasL is generated in Rac1-expressing cells after serum deprivation and it is necessary for apoptosis. (A) NIH 3T3 cells stably expressing Ras-1QL protein (Rac1) or control NIH 3T3 cells (Control) were incubated in DMEM with $(+)$ or without $(-)$ serum for $24 \mathrm{~h}$. Then, cells were processed for FasL expression determined by RT-PCR as described in MATERIALS AND METHODS. FasL expression in shown on the left (Fas Ligand), and as control, the $\beta$-actin expression ( $\beta$-Actin) was determined with the same samples in parallel reactions. Negative control refers to an RT-PCR amplification without primers. (B) Western blot analysis of FasL levels in NIH 3T3 and Rac1 cells in the presence and absence of serum. (C) Cells were incubated with FasFc $(0.2 \mu \mathrm{g} / \mathrm{ml})$ either in control medium or without serum for $24 \mathrm{~h}$. Cell death was estimated by flow cytometry (Annexin V) and expressed as percentage of the value of Rac1 without serum for each experiment (cell death range: 22-38\%). Data are the mean \pm SD from three independent experiments.

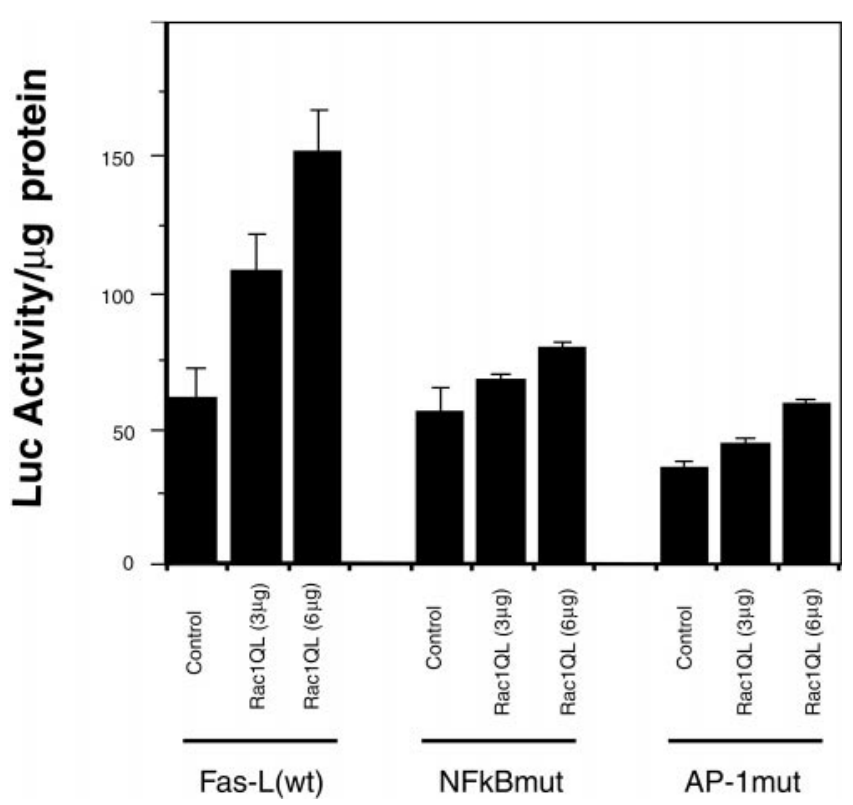

Figure 8. Rac1QL activates transcription of the hFasL promoter through the $\kappa \mathrm{B}$ and $\mathrm{AP}-1$ sites. NIH $3 \mathrm{~T} 3$ fibroblasts were cotransfected with increasing amounts of Rac1QL together with $3 \mu \mathrm{g}$ of the luciferase reporter constructs containing a 0.9-kb fragment of the human Fas L promoter (left), a mutated form deficient in NF- $\kappa$ B binding (middle), and a mutated form deficient in AP-1 binding (right). Luciferase activity was determined $24 \mathrm{~h}$ after transfection. Results are expressed as luciferase activity per milligram of protein extracts. Overexpression of Rac1QL in NIH 3T3 cells induces transcriptional activation of the FasL promoter in a dose-dependent manner (left). Transcriptional regulation of the $\mathrm{hFasL}$ promoter by Rac1QL is dependent on functional $\kappa \mathrm{B}$ (middle) and AP-1 (right) sites. Data represent the mean of a single experiment performed in triplicate \pm SD. Same results were observed in three independent experiments.

dent) may be required for Rac1-mediated induction of the Fas ligand promoter.

\section{Ceramides and FasL Cooperate in Rac-mediated Apoptosis}

Because both ceramide levels and FasL levels appear to be up-regulated in serum-starved Rac1-overexpressing cells, we next wanted to assess the effects of these two signaling components and their possible relationship during induction of cell death. To that end, we incubated cells in the presence of FasL along with 10\% serum (NCS). Different concentrations were tested, and incubation proceeded up to $48 \mathrm{~h}$. Treatment of the cells with FasL was not sufficient to induce apoptosis under any condition tested (our unpublished results). However, when this incubation was carried out in the absence of serum, the Rac1-QL cells underwent apoptosis much earlier with regard to the untreated cells in an interval from 15 to $16 \mathrm{~h}$ upon treatment (Figure 9A), that is, 5-6 h earlier that cells deprived of serum in the absence of FasL. Incubation of the parental cells. NIH 3 T3 cells, with the permeable synthetic ceramide $\mathrm{C} 2$ in the presence of serum during $48 \mathrm{~h}$ had no effect in the induction of apoptosis 


\section{A}

Figure 9. Induction of apoptosis by exogenous addition of FasL and/or synthetic ceramides. Analysis of DNA fragmentation was performed essentially as described in MATERIALS AND METHODS. Control, NIH 3T3 cells, and NIH 3T3 overexpressing Rac1 were incubated in DMEM supplemented with $10 \%$ NCS until they reached $70 \%$ confluence. At this time, cells were incubated in DMEM with (+) or without $(-)$ serum, and treated as follows. (A) Cells were incubated with Fas ligand $(50 \mathrm{ng} / \mathrm{ml})$ in the absence or presence of serum for $19 \mathrm{~h}$. (B) Cells were incubated with $\mathrm{C}_{2}$ ceramide $(100 \mu \mathrm{M})$ in the presence or absence of serum for 48 h. (C) Cells were incubated with Fas ligand $(50 \mathrm{ng} / \mathrm{ml})$ plus ceramides $\mathrm{C}_{2}(100 \mu \mathrm{M})$ in the presence or absence of $10 \%$ NCS for $24 \mathrm{~h}$.
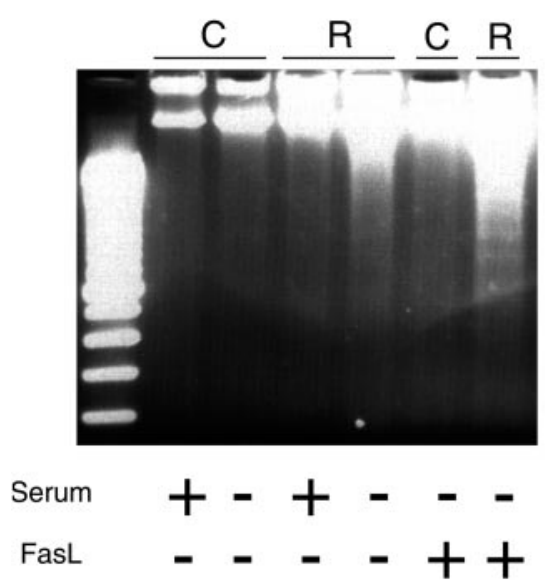

TIME
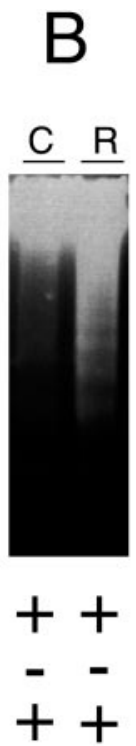

$48 \mathrm{~h}$
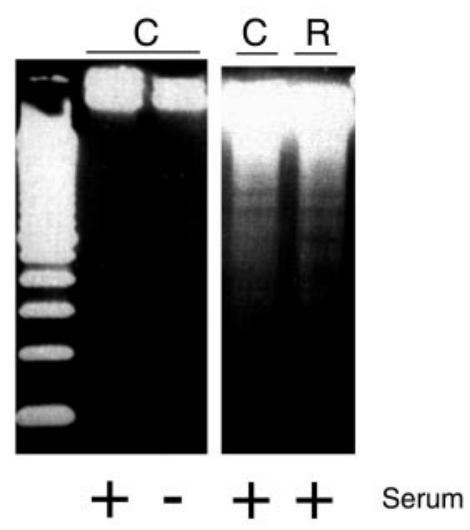

- ++ FasL

- ++ Ceramides

$24 \mathrm{~h}$
(Figure 9B). In contrast, when cells expressing the Rac1 protein were treated with the permeable synthetic ceramide $\mathrm{C} 2$ under similar conditions, it was sufficient to induce massive DNA fragmentation (Figure 9B).

The above-mentioned results demonstrate that neither FasL nor ceramides alone are sufficient to trigger apoptosis in NIH 3T3 cells. Therefore, these cells do not have the complete machinery for induction of apoptosis by either ceramides or FasL. However, in cells overexpressing the Rac1 protein, addition of either ceramides or FasL was sufficient for a massive induction of apoptosis. Thus, the presence of these two signals seems to play an important role in the induction of apoptosis in this cellular system. These results suggest that at least two complementary signals are required for the induction of apoptosis in NIH 3T3 cells. Because Rac1 provides both the generation of ceramides and the synthesis de novo of FasL, a possible explanation was that the mechanism for induction of apoptosis by Rac1 involved the simultaneous activation of these two signals.

To test this hypothesis, we incubated the parental NIH $3 T 3$ cells with FasL and ceramides for $24 \mathrm{~h}$ in the presence of serum. As shown in Figure 9C, apoptosis was triggered, shown by the appearance of a DNA ladder similar to that of the Rac1 cells after serum deprivation. Thus, the simultaneous addition of ceramides and FasL to the parental NIH 3T3 cells produced an equivalent effect to serum withdrawal in the Rac1 cells, resulting in the induction of apoptosis.

\section{DISCUSSION}

The superfamily of small GTPases regulates signaling pathways that underlie a wealth of activities, including growth and differentiation, in organisms ranging from yeast to humans. Although Rho proteins, a family of small GTPases, were initially shown to have a role in cytoskeletal remodeling, it is now known that these GTPases are involved in several other cellular processes such as transcriptional activation, growth control, metastasis, development, and apoptosis.

Our group provided the first evidence that Rho proteins could be implicated in the regulation of apoptosis (Jiménez et al., 1995). Expression of the A. californica Rho protein (which primary structure is $95 \%$ identical to the human RhoA protein), into NIH 3T3 murine fibroblasts, induced apoptosis after serum deprivation. Since this first report, several groups have also reported both positive and negative involvement of Rho proteins in apoptotic program, depending on the cell line investigated. Thus, human RhoA, RhoC, Rac1, Rac2, and Cdc42 proteins have been involved in the induction of apoptosis in diverse cellular systems, including fibroblasts (Esteve et al., 1998), thymocytes (Lores et al., 1997), neurons (Bazenet et al., 1998), and epithelial cells (Fiorentini et al., 1998). However, the precise mechanism involved was still not resolved. Here, we provide evidence of some of the critical signaling pathways by which Rac1 may induce apoptosis.

The results presented in this study demonstrate that Rac1 can induce apoptosis by a mechanism that involves protein and mRNA synthesis, activates caspase-3, but not caspase-1, and may require the simultaneous production of ceramides and the synthesis of FasL by a complex mechanism that involves JNK- and NF- $\kappa \mathrm{B}$-dependent signals. However, no significant release of cytochrome $c$ from mitochondria was observed before the onset of the apoptotic program, suggesting a pathway independent of cytochrome $c$ release. In keeping with this, hyperpolarization of the mitochondria and generation of ROS was observed.

The murine fibroblasts cell line NIH 3T3, is not sensitive to ceramides or FasL alone, but it is sensitive to the combined action of both signals. NIH 3T3 cells expressing the Rac1 protein constitutively activate JNK and NF- $\kappa$ B signaling pathways, even in the presence of serum (Perona et al., 1997; 
Montaner et al., 1998, 1999). Upon serum removal, production of ceramides and FasL is observed, and the cells undergo apoptosis. Finally, specific growth factors such as PDGF or FGF efficiently inhibit the apoptotic response. From these findings, we propose that Rac1 provides simultaneous and specific cooperative signals for apoptosis. Moreover, cells expressing the Rac1 protein seem to be "initiated" because they are sensitive to ceramides, whereas parental cells are not. Therefore, we can postulate that both initiation and progression signals are needed in this cellular system to induce apoptosis. Both ceramides production and FasL synthesis would participate in this process as complementary, but not sufficient signals.

Ceramides act as second messengers and trigger apoptosis in many cell types. In FasL-sensitive cells, ceramide generation after receptor activation has been placed downstream of the death adaptor proteins (Chinnaiyan et al., 1996). In stress response and ceramide signaling, apoptosis involves a Ras/ceramide-activated protein kinase as well as the Ras, Raf-1, and MAPK ERK kinase (MEK) pathway. Akt is then inactivated, causing the phosphorylation of $\mathrm{Bcl}-\mathrm{XL} / \mathrm{Bcl} 2-$ associated death promoter (BAD), which executes its proapoptotic function by binding its antiapoptotic partner Bcl-2. This results in the release of cytochrome $c$ from mitochondria to the cytosol, triggering cell death. How cytochrome $c$ escapes from mitochondria during apoptosis remains controversial and more than one mechanism may be possible, depending on the particular stimulus and the type of cell involved (Green and Reed, 1998). Our results demonstrate that ceramides can trigger apoptosis in the Rac1-expressing cells but not in their parental counterparts. Furthermore, this process is independent of cytochrome $c$ release from mitochondria. Preliminary results indicated that sphingomyelin levels decreased in Rac-1 transfectant cells upon serum removal (Esteve et al., 1998), suggesting the involvement of an endogenous sphingomyelinase. However, attempts to identify the signaling mechanism responsible for ceramides production in Rac-transfectants were unsuccessful because neither glutathione nor desipramine, previously reported inhibitors of neutral and acidic sphingomyelinases in other cell types, affected sphingomyelinase activity in NIH 3T3 cells (our unpublished results). Furthermore, no inhibitory effect was observed when cells were treated with fumonisin B1, an inhibitor of ceramides synthesis, ruling out the possibility that ceramides production in Rac-1 cells was a consequence of ceramides synthesis. Thus, further research will be required to identify the specific enzymatic machinery involved and the participation of ceramides in this process.

The mechanism for Rac1-induced apoptosis is independent of cytochrome $c$ release. In fact, and consistent with this observation, we provide evidence that an increase of $\Delta \Psi \mathrm{m}$ constitutes an important event in Rac-1-induced apoptosis. This was confirmed by staining with both DioC6 and JC-1. Also, when we used the mitotracker CMXRos these cells exhibited high levels of red fluorescence after serum depletion (our unpublished results). A growing body of evidence indicates that a loss of $\Delta \Psi \mathrm{m}$ is an early step in apoptosis (Zamzami et al., 1995; Hortelano et al., 1997). However, recent studies suggest that it may not be a universal pathway and it depends on the cellular type (Bossy-Wetzel et al., 1997; Kim et al., 1997; Li et al., 1999; Samali et al., 1999). Furthermore, it is well known that ROS are implicated in the induction of apoptosis in several cell types (Li et al., 1999). Thus, our results indicate a lack of cytochrome $c$ involvement, and a potential role of ROS generation in Rac1-induced apoptosis, in keeping with recent results published by other authors with other systems. On this regard, apoptotic pathways have been described that are independent of cytochrome $c$ release. For instance, some stress signals and cytokines can initiate the apoptotic signal transduction pathway via JNK (reviewed in Basu and Kolesnick, 1998). Moreover, FasL can activate both death receptors and trigger caspase activation and subsequent proteolysis without any detectable changes in cytochrome $c$ cellular localization (Chang et al., 1998), consistent with the involvement of a FasL- or tumor necrosis factor- $\alpha$-dependent mechanism in Rac1-induced apoptosis.

Signaling by FasL seems to be important in Rac1-induced apoptosis. Several cell types can be activated to undergo apoptosis after the interaction of selected ligands with cell surface receptors. Among the death receptors, Fas (also called CD95) (Trauth et al., 1989; Yonehara et al., 1989) and the tumor necrosis factor receptor 1 (Bazzoni and Beutler, 1996) are the most well studied. Both trigger apoptosis upon binding to their ligands, which are structurally related molecules. Activation of Fas receptor can trigger apoptosis by mechanisms that involve or not cytochrome $c$ release (Boldin et al., 1995; Chinnaiyan et al., 1995; Stanger et al., 1995; Muzio et al. 1996; Salvesen and Dixit 1997; Susin et al., 1997; Li et al., 1998). Our results indicate that Rac1-induced apoptosis is consistent with a Fas-dependent mechanism. Expression of FasL induced by Rac1 was found to be controlled by the transcriptional activation of both JNK- and NF- $\kappa$ B-dependent signals, in agreement with recent findings that FasL promoter holds AP-1 and NF- $\kappa \mathrm{B}$ sites (Kasibhatla et al., 1998). Furthermore, inhibition of FasL by an antogonist, FasFc, strongly inhibited the induction of apoptosis by Rac1.

Both JNK and NF- $\kappa$ B play a critical role in Rac1-induced apoptosis as coordinated signals required for FasL promoter regulation. However, FasL was not sufficient to turn on the apoptotic program and required the collaboration of a second signal, which we proposed is the generation of ceramides. Because none of these events (FasL or ceramides) was sufficient to induce apoptosis in NIH 3T3 cells, we postulate the need of initiation and progression signals for apoptosis induced by Rac1. It is important to point out that in the Rac1 transfectants, there is a constitutive induction of JNK and NF- $\kappa$ B activity, which does not translate into an increase in FasL synthesis. Thus, additional negative or inhibitory signals that impinge into FasL translational regulation may be regulated by growth factors. In this sense, the initiation signal for apoptosis may imply JNK and NF- $\kappa \mathrm{B}$, but not FasL synthesis. Thus, specific growth factors (PDGF, FGF) may interfer with FasL production under conditions of JNK and NF- $\kappa$ B activation.

The results presented here represents an important progress in our understanding on how Rho proteins participate in the regulation of apoptosis. Further research should clarify those aspects that remain to be fully elucidated.

\section{ACKNOWLEDGMENTS}

We thank D. Green for the promoter of FasL. This work was supported by Grant FIS-99/0817, Grant 2FD97-0647 from Comision 
Interministerial de Ciencia y Tecnologia, and Grants 08.1/0024/97 and 08.1/0045.1/98 from Consejería de Educación of Comunidad de Madrid. P.F.V. is a recipient of a special grant from Consejería de Educación, Gobierno de Canarias.

\section{REFERENCES}

Ashkenazi, A., and Dixit, V.M. (1999). Apoptosis control by death and decoy receptors. Curr. Opin. Cell Biol. 11, 255-260.

Basu, S., and Kolesnick, R. (1998). Stress signals for apoptosis, ceramide and c-Jun kinase. Oncogene 17, 3277-3285.

Bazenet, C.E., Mota, M.A., and Rubin, L.L. (1998). The small GTPbinding protein cdc42 is required for nerve growth factor withdrawal-induced neuronal death. Proc. Natl. Acad. Sci. USA 95, 39843989.

Bazzoni, F., and Beutler, B. (1996). The tumor necrosis factor ligand and receptor families. N. Engl. J. Med. 334, 1717-1725.

Boldin, M.P., Mett, I.L., Varfolomeev, E.E., Chumakow, Y., ShemerAvin, Y., Camonis, J.H., and Wallach, D. (1995). Self-association of the "death domains" of the p55 tumor necrosis factor (TNF) receptor and Fas/APO1 prompts signaling for TNF and Fas/APO1 effects. J. Biol. Chem. 270, 387-391.

Bossy-Wetzel, E., Bakiri, L., and Yaniv, M. (1997). Induction of apoptosis by the transcription factor c-jun. EMBO J. 16, 1695-1709.

Chang H.Y., Nishitoh, H., Yang, X., Ichijo, H., and Baltimore, D. (1998). Activation of apoptosis signal-regulating kinase 1 (ASK1) by the adapter protein Daxx. Science 281, 1860-18063.

Chardin, P., Madaule, P., and Tavitian, A. (1988). Coding sequence of human rho cDNAs clone 6 and clone 9. Nucleic Acids Res. 16, 2717.

Chinnaiyan, A., O'Rourke, K., Tewari, M., and Dixit, V.M. (1995). FADD, a novel death domain-containing protein, interacts with the death domain of Fas and initiates apoptosis. Cell 81, 505-512.

Chinnaiyan A.M., Tepper, C.G., Seldin, M.F., O'Rourke, K., Kischkel, F.C., Hellbardt, S., Krammer, P.H., Peter, M.E., and Dixit, V.M. (1996). FADD/MORT1 is a common mediator of CD95 (Fas/Apo1) and tumor necrosis factor receptor-induced apoptosis. J. Biol. Chem. 271, 4961-4965.

Chuang, T.H., Hahn, K.M., Lee, J.D., Danley, D.E., and Bokoch, G.M. (1997). The small GTPase Cdc42 initiates an apoptotic signaling pathway in Jurkat T lymphocytes. Mol. Biol. Cell 9, 1687-1698.

Cotman, C.W., and Anderson, A.J. (1995). A potential role for apoptosis in neurodegeneration and Alzheimer's disease. Mol. Neurobiol. 10, 19-45.

Crespo P., Bustelo, X., Aaronson, D., Coso, O., Lopez-Barahona, M., Barbacid, M., and Gutkind, S. (1996). Rac-1 dependent stimulation of the JNK/SAPK signaling pathway by Vav. Oncogene 13, 455460 .

Didsbury, J., Weber, R.F., Bokoch, G.M., Evans, T., and Snydermand, R. (1989). rac, a novel ras-related family of proteins that are botulinum toxin substrates. J. Biol. Chem. 264, 16378-16382.

Esteve P., del Peso, L., and Lacal, J.C. (1995). Induction of apoptosis by rho in NIH-3T3 cells requires two complementary signals. Ceramides function as a progression factor for apoptosis. Oncogene 11, $2657-2665$

Esteve, P., Embade, N., Perona, R., Jiménez, B., del Peso, L., León, J., Arends, M., Miki, T., and Lacal, J.C. (1998). Rho-regulated signals induce apoptosis in vitro and in vivo by a p53-independent, but Bcl-2 dependent pathway. Oncogene 17, 1855-1869.

Fan, Y.Y., Zhang, J., Barhoumi, R., Burghardt, R.C., Turner, N.D., Lupton, J.R., and Chapkin, R.S. (1999). Antagonism of CD95 signal- ing blocks butyrate induction of apoptosis in young adult mouse colonic cells. Am. J. Physiol. 277, 310-319.

Fiorentini, C., Matarrese, P., Straface, E., Falzano, L., Donelli, G., Boquet, P., and Malorni, W. (1998). Rho dependent cell spreading activated by E. coli cytotoxic necrotizing factor 1 hinders apoptosis in epithelial cells. Cell Death Differ. 5, 921-929.

Green, D.R. (1998). Apoptotic pathways: the roads to ruin. Cell 94, 695-698.

Green, D.R., and Reed, J.C. (1998). Mitochondria and apoptosis. Science 281, 1309-1312.

Gulbins, E., Coggeshall, K.M., Brenner, B., Schlottmann, K., Linderkamp, O., and Lang, F. (1996). Fas-induced apoptosis is mediated by activation of a Ras and Rac protein-regulated signaling pathway. J. Biol. Chem. 271, 26389-26394.

Haataja, L., Groffen, J., and Heisterkamp, N. (1997). Characterization of RAC3, a novel member of the Rho family. J. Biol. Chem. 272, 20384-20388.

Hannun, Y.A. (1994). The sphingomyelin cycle ant the second messenger function of ceramide. J. Biol. Chem. 269, 3125-3128.

Horii, Y., Beeler, J., Sakaguchi, K., Tachibana, M., and Miki, T. (1994). A novel oncogene, ost, encodes a guanine nucleotide exchange factor that potentially links Rho and Rac signaling pathways. EMBO J. 13, 286-291.

Hortelano, S., Dallaporta, B., Zamzanmi, N., Hirsch, T., Susin, S.A., Marzo, I., Boscá, L., and Kroemer, G. (1997). Nitric oxide induces apoptosis via triggering mitochondrial permeability transition. FEBS Lett. 410, 373-377.

Jarvis, W.D., Kolesnick, R.N., Fornari, F.A., Traylor, R.S., Gerwitrtz, D.A., and Grant, S. (1994). Induction for apoptotic DNA damage and cell death by activation of the sphingomyelin pathway. Proc. Natl. Acad. Sci. USA 91, 73-77.

Jiménez, B., Arends, M., Esteve, P., Perona, R., Sanchez, Y., Ramón y Cajal, S., Wyllie, A., and Lacal, J.C. (1995). Induction of apoptosis in NIH3T3 cells after serum deprivation by overexpression of rhop21, a GTPases protein of the ras superfamily. Oncogene 10, 811816.

Kasibhatla, S., Brunner, T., Genestier, L., Echeverri, F., Mahboubi, A., and Green, D.R. (1998). DNA damaging agents induce expression of Fas ligand and subsequent apoptosis in T lymphocytes via the activation of NF-kappaB and AP-1. Mol. Cell 1, 543-551.

Kim, C.N., Wang, X., Huang, Y., Ibrado, A.M., Liu, L., Fang, G., and Bhalla, K. (1997). Overexpression of Bcl-X(L) inhibits Ara-C-induced mitochondrial loss of cytochrome $\mathrm{c}$ and other perturbations that activate the molecular cascade of apoptosis. Cancer Res. 57, 31153120.

Kluck, R.M., Martin, S.J., Hoffman, B.M., Zhous, J.S., Green, D.R., and Newmeyer, D.D. (1997). Cytochrome c activation of CPP32-like proteolysis plays a critical role in Xenopus cell-free apoptosis system. EMBO J. 16, 4639-4649.

Krippner, A., Matsuno-Yagi, A., Gottelieb, R.A., and Babios, B.M. (1996). Loss of function of cytochrome $\mathrm{c}$ in jurkat cells undergoing Fas-mediated apoptosis. J. Biol. Chem. 271, 21629-21636.

Li, P.-F., Rainer, D., and Harsdorf, R. (1999). p53 regulates mitochondrial membrane potential through reactive oxygen species and induces cytochrome c-independent apoptosis blocked by Bcl-2. EMBO J. 18, 6027-6036.

Li, H., Zhu, H., Xu, C-J., and Yuan, J. (1998). Cleavage of BID by caspase 8 mediates the mitochondrial damage in the Fas pathway of apoptosis. Cell 94, 491-501.

Liu, X., Kim, C.M., Yang, J., Jemmerson, R., and Wang, X. (1996). Induction of apoptotic program in cell-free extracts: requirement for dATP and cytochrome C. Cell 86, 147-157. 
López-Collazo, E., Hortelano, S., and Boscá, L. (1998). Interferonalpha/beta inhibits the apoptosis induced by lipopolysaccharide and interferon-gamma in murine peritoneal macrophages. J. Interferon Cytokine Res. 18, 461-467.

Lores, P., Morin, L., Luna, R., and Gacon, G. (1997). Enhanced apoptosis in the thymus of transgenic mice expressing constitutively activated forms of human Rac2 GTPase. Oncogene 15, 601-605.

Madaule, P., and Axel, R. (1985). A novel ras-related gene family. Cell 41, 31-40.

Martin, S.J., Green, D.R., and Cotter, T.G. (1994). Dancing with death: dissecting the components of the apoptosis machinery. Trends Biochem. Sci. 19, 26-30.

Montaner, S., Perona, R., Saniger, L., and Lacal, J.C. (1998). Multiple signaling pathways lead to the activation of the nuclear factor $\kappa \mathrm{B}$ by the Rho family of GTPases. J. Biol. Chem. 273, 12779-12785.

Montaner, S., Perona, R., Saniger, L., and Lacal, J.C. (1999). Activation of the serum response factor (SRF) by Rho A is mediated by the activity of NF-kB and c/EBP families of transcription factors. J. Biol. Chem. 274, 8506-8515.

Muzio, M., Chinnaiyan, A.M., Kischekel, F.C., O'Rourke, D., Shevchenko, A., Ni, J., Scaffidi, C., Bretz, F.D., Shang, M., Gentz, R., Mann, M., Krammer, P.H., Peter, M.E., and Dixit, V.M. (1996). FLICE, a novel FADD-homologous ICE/CED-3-like proteases is recruited to the CD95 (Fas/APO-1) death-inducing signaling complex. Cell 85, 817-827.

Nicholson, D.W., Ali, A., Thornberry, N.A., Vaillancourt, J.P., Ding, C.K., Gallant, M., Gareau, Y., Griffin, P.R., Labele, M., Lazebnik, Y.A., Munday, N.A., Raju, S.M., Smulson, E., Yamin, T.-T., Yu, V.L., and Miller, D.K. (1995). Identification and inhibition of the ICE/ CED-3 protease necessary for mammalian apoptosis. Nature 376, 37-43.

Nuñez, G., Benedict, M.A., Hu, Y., and Inohara, N. (1998). Caspases: the proteases of the apoptotic pathway. Oncogene 17, 3227-3245.

Obeid, L.M., Linardic, C.M., Karolak, L.A., and Hannun, Y. (1993). Programmed cell death induced by ceramide. Science 259, 17691771.

Perona, R., Montaner, S., Saniger, L., Sánchez-Pérez, I., Bravo, R., and Lacal, J.C. (1997). Activation of the nuclear factor $\kappa$ B by Rho, CDC42 and Rac. Genes Dev. 11, 463-475.

Salvesen, G.S., and Dixit, V.M. (1997). Caspases: intracellular signaling by proteolysis. Cell 91, 443-446.

Samali, A., Cai, J., Zhivotovsky, B., Jones, D.P., and Orrenius, S. (1999). Presence of a pre-apoptotic complex of pro-caspase-3, Hsp60 and Hsp10 in the mitochondrial fraction of Jurkat cells. EMBO J. 18, 2040-2048

Shinjo, K., Koland, M.J.G., Hart, M.J., Narasimhan, V., Johnson, D.I., Evans, T., and Cerione, R. (1990). Molecular cloning of the gene for that human placental GTP-binding protein Gp (G25K): identification of this GTP-binding protein as the human homolog of the yeast cell-division -cycle protein CDC42. Proc. Natl. Acad. Sci. USA 87, 9853-9857.

Stanger, B.Z., Leder, P., Lee, T.-H., Kim, E., and Seed, B. (1995). RIP: a novel protein containing a death domain that interacts with Fas/ APO-1 (CD95) in yeast and causes cell death. Cell 81, 513-523.

Susin, S.A., Zamzami, N., Castedo, M., Dauas, E., Wang, H.G., Geley, S., Fassy, F., Reed, J.C., and Kroemer, G. (1997). The central executioner of apoptosis: multiple connections between protease activation and mitochondria in Fas/APO-1and ceramide-induced apoptosis. J. Exp. Med. 186, 25-37.

Tapon, N., Nagata, K-I., Lamarche, N., and Hall, A. (1998). A new rac target $\mathrm{POSH}$ is an $\mathrm{SH} 3$ containing scaffold protein involved in the JNK and NF-kappaB signaling pathways. EMBO J. 17, 13951404.

Testi, R. (1996). Sphingomyelin breakdown and cell fate. Trends Biochem. Sci. 21, 468-471.

Thornberry, N.A., and Lazebnik, Y. (1998). Caspases: enemies within. Science 281, 1312-1316.

Thompson, C.B. (1995). Apoptosis in the pathogenesis and treatment of disease. Science 267, 1456-1462.

Trauth, B.C., Klas, C., Peters, A.M., Matzuki, S., Moller, P., Falk, W., Debatin, K-M., and Krammer, P.H. (1989). Monoclonal antibodymediated tumor regression by induction of apoptosis. Science 245 , 301-305.

Van Aelst, L., and D'Souza-Schorey, C. (1997). Rho GTPases and signaling networks. Genes Dev. 11, 2295-2322.

Vincent, S., Jeanteur, P., and Fort, P. (1992). Growth-regulated expression of rhoG, a new member of the ras homolog gene family. Mol. Cell. Biol., 12, 3138-3148.

White, E. (1996). Life, death and the pursuit of apoptosis. Genes Dev. 10, 1-15.

Yonehara, S., Ishii, A., and Yonehara, M. (1989). A cell-killing monoclonal antibody (anti-Fas) to a cell surface antigen co-downregulated with the receptor of tumor necrosis factor. J. Exp. Med. 169, 1747-1756

Yang, J., Liu, X., Bhalla, K., Kim, C.N., Ibrado, A.M., Cai, J., Peng, T.I., Jones, D.P., and Wang, X. (1997). Prevention of apoptosis by Bcl-2: release of cytochrome c from mitochondria blocked. Science $275,1129-1132$

Zamzami, N., Marchetti, P., Castedo, M., Zanin, C., Vayssiere, J.L., Petit, P.X., and Kroemer, G. (1995). Reduction in mitochondrial potential constitutes an early irreversible step of programmed lymphocyte death in vivo. J. Exp. Med. 181, 1661-1672. 